\title{
Invasion Genetics of the Chestnut Blight Fungus Cryphonectria parasitica in Switzerland
}

\author{
S. Prospero and D. Rigling
}

WSL Swiss Federal Research Institute, Zuercherstrasse 111, CH-8903 Birmensdorf, Switzerland. Accepted for publication 3 August 2011.

\begin{abstract}
Prospero, S., and Rigling, D. 2012. Invasion genetics of the chestnut blight fungus Cryphonectria parasitica in Switzerland. Phytopathology 102:73-82.

Cryphonectria parasitica is the best-known example of an invasive forest pathogen in Europe. In southern Switzerland, chestnut blight was first reported in 1948 whereas, north of the Alps, it did not appear until the 1980s. Between 1995 and 2008, we sampled 640 C. parasitica isolates from nine populations south of the Alps and nine north of the Alps. Twelve historical isolates, collected between 1950 and 1972 in the south,

fied. Structure software analysis indicated that 43 haplotypes (including all historical haplotypes) belonged to a main cluster, 6 haplotypes belonged to a different cluster, and 3 haplotypes had an intermediate allele pattern. All newly founded populations in northern Switzerland were initiated by one or just a few haplotypes from the main cluster, which probably came directly from the populations south of the Alps. Subsequently, genetic diversity increased through mutations, sexual reproduction, or new migrations. The highest increase in diversity was observed in populations where haplotypes from different genetic pools were encountered.
\end{abstract} were obtained from our collection. All 652 isolates were screened at 10 microsatellite loci to test for the existence of divergent genetic pools and to infer possible origins of haplotypes. In total, 52 haplotypes were identi-
Additional keywords: admixture, clonality, fungal pathogen, introduction.
Invasive species receive considerable scientific attention because of the dramatic ecological impacts they may have on ecosystems outside their natural range $(4,23)$. Exotic pathogens especially may negatively affect native ecosystems by changing their structure, altering biological interactions, or increasing their susceptibility to stress $(40,49,61)$. Because introductions of exotic pathogens to new areas are the direct or indirect result of human activities, increasing world trade and traveling will probably lead to higher future introduction rates of invasive pathogens (22, $35,63)$. Therefore, detailed knowledge about the population dynamics of invasive pathogens is crucial to develop sustainable control strategies. In particular, knowing the population genetic structure may provide relevant insights into the colonization history and spread of invasive species (i.e., invasion genetics) (58).

Cryphonectria parasitica (Ascomycete), the causal agent of chestnut blight, is one of the best-known invasive fungal pathogens in forest ecosystems. Following its introduction from Asia at the beginning of the 20th century, $C$. parasitica almost caused the extinction of the American chestnut (Castanea dentata) in the eastern United States (3). In Europe, the pathogen was first recorded in Italy in 1938 (32) and, today, is present in all main chestnut areas (55). In contrast to the United States, infected European chestnut (C. sativa) stands have recovered from the disease in many areas due to naturally occurring hypovirulence caused by a hyperparasitic fungal virus $(16,32,46,55)$.

In Switzerland, chestnut blight was first observed in 1948 south of the Alps, adjacent to northern Italy (32). Here, European chestnut is the dominant tree species up to $\approx 900 \mathrm{~m}$ above sea level,

Corresponding author: S. Prospero; E-mail address: simone.prospero@wsl.ch

* The $\boldsymbol{e}$-Xtra logo stands for "electronic extra" and indicates that the online version contains two supplementary tables. Figure 1 appears in color online.

http://dx.doi.org/10.1094/PHYTO-02-11-0055

(C) 2012 The American Phytopathological Society forming a more-or-less continuous forest belt of $\approx 30,000$ ha (17). Healing chestnut blight cankers were first reported in 1975, and natural hypovirulence is currently widespread (11). Previous investigations based on vegetative incompatibility, a phenotypic marker, have shown that Cryphonectria parasitica populations in southern Switzerland present diversity patterns similar to those in northern Italy or southeastern France (i.e., to those in areas where the pathogen was first introduced into Europe) $(19,55)$. The presence of the two mating types and the high abundance of perithecia suggest that sexual reproduction of $C$. parasitica occurs in southern Switzerland $(11,34,52)$.

North of the Swiss Alps, a colder climate and calcareous bedrock are limiting the occurrence of European chestnut. Consequently, stands are scattered and occur only in mild regions along major lakes (Lucerne, Walenstadt, Zug, and Geneva) and in the Rhone (Cantons Valais and Vaud) and Rhine valleys. Despite quarantine regulations prohibiting the transport of chestnut plant material to northern Switzerland, the first blighted stands were found close to Monthey and Lucerne in the 1980s (10). Today, chestnut blight is present in all main chestnut areas north of the Swiss Alps (33). In most chestnut stands, low diversity of vegetative compatibility (vc) types is observed (34), similar to that in other European regions where $C$. parasitica has recently been introduced; for example, Turkey (2) Portugal (13), and Macedonia (60).

In $C$. parasitica, the application of vegetative incompatibility (vic) has limitations in investigations of invasion genetics because (i) several genetically distinct individuals (haplotypes) can possess the same vc type $(14,39)$, (ii) vic loci may be under selective pressure to prevent the transmission of fungal viruses (45), and (iii) the vic genotypes are not known for all vc types found in Europe (54). In contrast, microsatellites (simple-sequence repeats), which are selectively neutral and highly variable, have proven to be useful markers for studying the invasion genetics of fungal populations. For example, Milgroom et al. (48) showed that southeastern Europe was colonized by a few $C$. parasitica 
clones. On the other hand, Dutech et al. (25) recorded the presence of three divergent $C$. parasitica lineages in France, which suggests that multiple introductions of the pathogen had occurred.

In order to assess the colonization history and the spread of $C$. parasitica in northern and southern Switzerland, we investigated the population genetic structure of this pathogen using the same microsatellites as Dutech et al. (25) for haplotype discrimination. Specifically, we addressed the two following questions: (i) how did the genotypic diversity of $C$. parasitica change in southern Switzerland following the introduction of the pathogen in the 1940s and (ii) did the $C$. parasitica haplotypes found north and south of the Swiss Alps originate from the same gene pool? Based on allelic patterns, we further inferred the importance of multiple introductions, sexual reproduction, and mutation as sources of new microsatellite haplotypes in $C$. parasitica.

\section{MATERIALS AND METHODS}

Study sites and sampling. We analyzed $18 C$. parasitica populations from the most important chestnut areas in Switzerland, both south ( 9 populations) and north ( 9 populations) of the Alps (Fig. 1; Table 1). We considered these populations to be representative of the whole Swiss $C$. parasitica distribution. Distances between populations were 2 to $290 \mathrm{~km}$. The chestnut stands (coppice, orchards, or mixed stands) ranged in age from 5 to $>100$ years old (Table 1).

At each study site, bark samples were taken with a fine bonemarrow biopsy needle ( $2 \mathrm{~mm}$ in diameter) from 15 to 30 randomly selected cankers of $C$. parasitica. To avoid sampling clones, only one canker per tree was chosen, and selected trees were separated by $\geq 5 \mathrm{~m}$. The presence or absence of perithecia (sexual fruiting bodies) on the sampled cankers was recorded.

To obtain information on the genetic composition of $C$. parasitica in Switzerland just after its first detection south of the Alps, all $(N=12)$ old isolates from the mycological culture collection of WSL (Birmensdorf, Switzerland) were also analyzed. These historical isolates were sampled between 1950 and 1972 in the Canton of Ticino (southern Switzerland) and the neighboring Italian Province of Lombardy.

Isolation, culture, and DNA extraction. For $C$. parasitica isolation, bark samples were dipped in $70 \%$ ethanol, briefly flamed, and placed on $1.5 \%$ water agar. After 5 to 7 days of incubation at room temperature in the dark, mycelia were transferred onto potato dextrose agar (PDA) (39 g/liter; Difco Laboratories, Detroit) and grown as described by Hoegger et al. (34). Genomic DNA was extracted from $10 \mathrm{mg}$ of lyophilized mycelium following the protocol of Gardes and Bruns (29).

Mating type identification. Mating types were identified by polymerase chain reaction (PCR) amplification of the two idiomorphs of the MAT locus using the primer pairs M1-GS1/M1GS2-rev for MAT-1 and M2-GS2/InvA5n for MAT-2 (43). PCR reactions were carried out in 50- $\mu \mathrm{l}$ volumes with final concentrations of $1 \times$ PCR buffer, $2 \mathrm{mM} \mathrm{MgCl} 2,200 \mu \mathrm{M}$ dNTPs, $0.2 \mu \mathrm{M}$ of each primer, $1 \mathrm{U}$ of Taq polymerase, and $1 \mu \mathrm{l}$ of DNA $(\approx 50$ to $200 \mathrm{ng}$ ). Cycling conditions were set to one cycle of $95^{\circ} \mathrm{C}$ for $3 \mathrm{~min} ; 30$ cycles of $95^{\circ} \mathrm{C}$ for $30 \mathrm{~s}, 66^{\circ} \mathrm{C}$ for $1 \mathrm{~min}$, and $72^{\circ} \mathrm{C}$ for $4 \mathrm{~min}$; and a final extension at $72^{\circ} \mathrm{C}$ for $10 \mathrm{~min}$. A DNA sample from a known MAT-1 and a known MAT-2 isolate were used as positive controls. PCR product $(3 \mu \mathrm{l})$ was run on $1.5 \%$ agarose

\section{Occurrence of European chestnut}

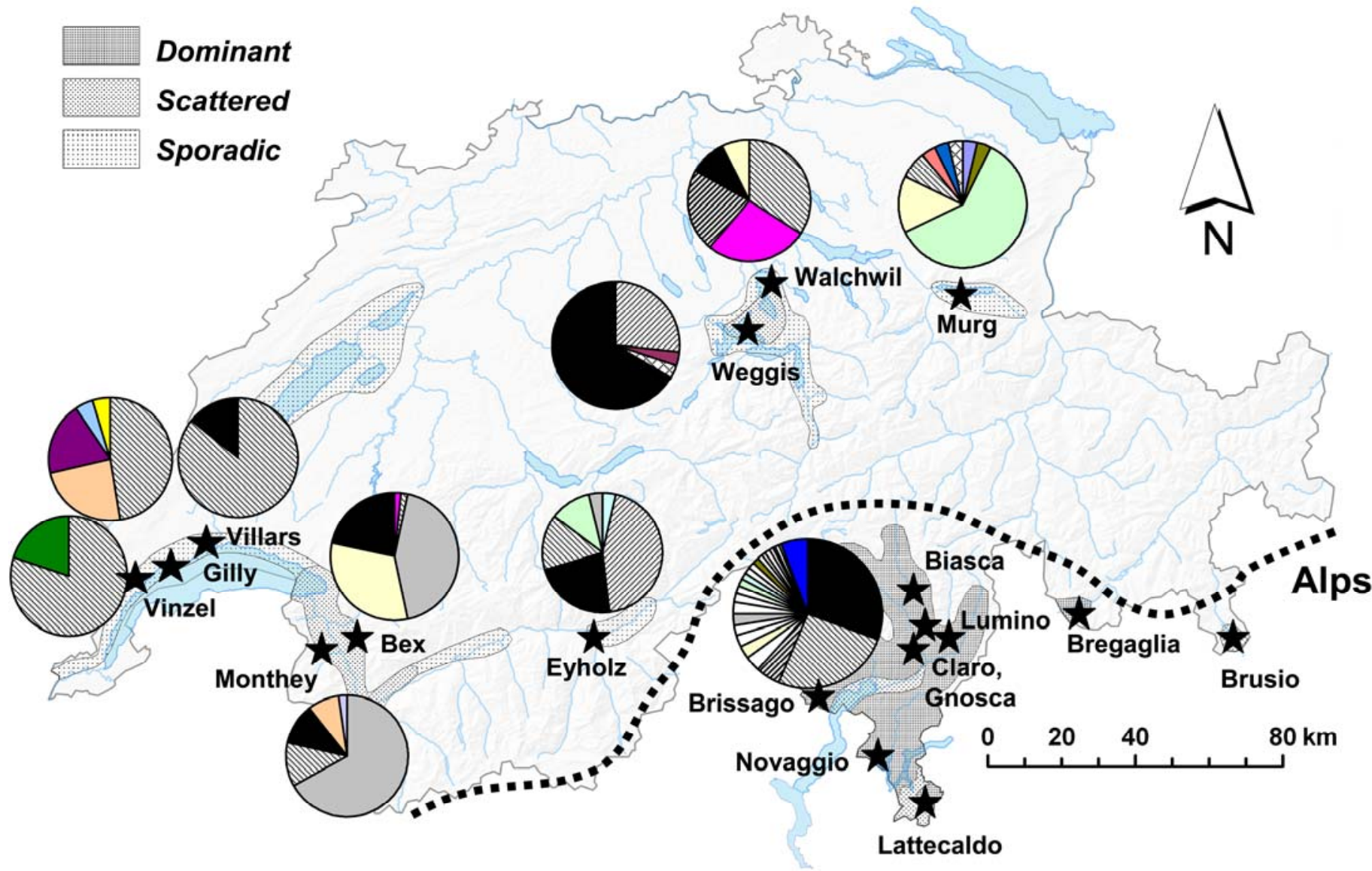

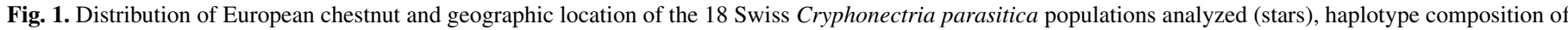

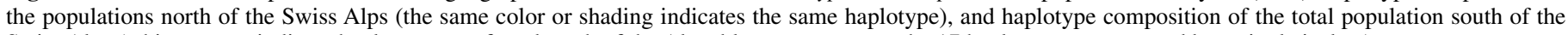
Swiss Alps (white sectors indicate haplotypes not found north of the Alps; blue sector groups the 17 haplotypes represented by a single isolate). 
gels to reveal the presence or absence of MAT-1 $(2.3 \mathrm{~kb})$ or MAT-2 (2 kb) fragments.

Microsatellite haplotypes. In total, 652 isolates were screened at 10 microsatellite loci previously developed for $C$. parasitica (CPG3, CPG4, CPE1, CPE3, CPE4, CPE5, and CPE8 [14]; CPG6 and CPG14 [37]; and I07-650 [21]). All loci were amplified using a denaturating cycle of $95^{\circ} \mathrm{C}$ for $15 \mathrm{~min}$; followed by 30 cycles of $94^{\circ} \mathrm{C}$ for $30 \mathrm{~s}, 58^{\circ} \mathrm{C}$ for $90 \mathrm{~s}$, and $72^{\circ} \mathrm{C}$ for $90 \mathrm{~s}$; and a final extension of $72^{\circ} \mathrm{C}$ for $30 \mathrm{~min}$. Multiplex PCR reactions targeting three to four loci (reaction 1: CPE3, CPE4, and CPG6; reaction 2: CPE8, CPG3, and I07-650; reaction 3: CPG4, CPE1, CPG14, and CPE5) were performed in $10-\mu$ l volumes containing $1 \times$ Multiplex PCR Master Mix (Qiagen, Valencia, CA), $0.1 \mu \mathrm{M}$ each primer $(0.2 \mu \mathrm{M}$ for CPE4), and $1 \mu \mathrm{l}$ of DNA diluted 1:20 ( $\approx 10$ to $50 \mathrm{ng}$ ). The $5^{\prime}$ end of each forward primer was marked with a fluorescent dye (FAM-blue or HEX-green) and amplification products were run on an ABI 3730 sequencer (Applied Biosystems, Carlsbad, CA), using ROX-400 as the internal size standard. Allele sizes were scored with the program GENEMAPPER (Applied Biosystems).

Data analysis. To verify that identical haplotypes in a population belonged to the same clone and were not derived by chance from sexual reproduction (26), the $P_{\text {sex }}$ value was estimated using GenClone version 2.0 (5).

Genetic diversity within populations was characterized by the number of haplotypes observed (Hap $\left.{ }_{\mathrm{Obs}}\right)$, the number of haplotypes expected in a sample of $N=20$ isolates (i.e., the smallest population being analyzed) $\left(\operatorname{Hap}_{\mathrm{Exp}}\right)$, the frequency of the most frequent haplotypes, the number of polymorphic loci (i.e., loci with more than one allele), the mean number of alleles observed per locus $\left(N_{\mathrm{A}}\right)$, and the allelic richness averaged across loci (based on a sample size of two haplotypes which corresponds to the smallest population being analyzed; $\left.A_{\mathrm{R}}\right)$. Hap $_{\operatorname{Exp}}$ was calculated using Raup's (53) rarefaction method as implemented in Analytic Rarefaction 1.3 (www.uga.edu/ strata/software/Software.html), and the indices $N_{\mathrm{A}}$ and $A_{\mathrm{R}}$ were calculated with FSTAT 2.9.3.2 (30). Differences in $\mathrm{Hap}_{\text {Exp }}$ and $A_{\mathrm{R}}$ between populations south and north of the Alps were tested for significance $(P<0.05)$ by conducting a Student's $t$ test.
The occurrence and frequency of sexual reproduction in the $C$. parasitica populations were indirectly estimated by the clonal fraction (isolates representing clones of haplotypes, $C_{\mathrm{f}}=\mathrm{N}-$ $\mathrm{Hap}_{\mathrm{Obs}} / N$, where $N$ is the sample size), by the maximal number of haplotypes expected assuming random recombination between the two most common haplotypes $\left(\operatorname{Hap}_{\text {MaxTwo }}=2^{k}\right.$, where $k$ is the number of loci that are polymorphic between the two most common haplotypes), by the presence or absence of perithecia on sampled cankers, and by the mating type ratio (MAT-1:MAT-2). For each population, the ratio MAT-1:MAT-2 was tested for significant $(P<0.05)$ deviation from equality by conducting a $\chi^{2}$ test. In addition, random mating among haplotypes was tested using the index of association statistics (1). In completely panmictic populations, the index of linkage disequilibrium among loci $r_{\mathrm{d}}$ has a value of zero, whereas largely clonal populations have $r_{\mathrm{d}}$ values close to 1 (gametic disequilibrium). Statistical significance was evaluated by comparing the observed $r_{\mathrm{d}}$ values with those obtained from 1,000 randomized data sets in which alleles were permuted among haplotypes (15) as implemented in Multilocus version 1.3 (1). Because clonality can influence the outcome of Multilocus, the analysis was performed both with only one representative isolate of each microsatellite haplotype and with all isolates.

The extent of genetic differentiation was estimated using Wright's $F$ statistics (62). The relationship between the genetic similarity and the geographical distance between pairs of $C$. parasitica populations in southern Switzerland was assessed by analyzing the regression of $F_{\mathrm{ST}} /\left(1-F_{\mathrm{ST}}\right)$ on the natural logarithm of geographic distance (57). The significance of the regression was tested with a Mantel (41) test (5,000 permutations) implemented in Genetix v.4.03 (9).

To test for the presence of different $C$. parasitica genetic pools in Switzerland, haplotypes were assigned to different clusters using a Bayesian clustering method implemented in the software Structure 2.3.2 (51). The probability of the admixture model (28) was tested for 1 to 10 clusters. Each model was simulated 10 times, with a burn-in of 100,000 iterations and a run length of $1,000,000$ iterations after the burn-in. To link our results to those obtained by Dutech et al. (25) in France, the seven most frequent

TABLE 1. Cryphonectria parasitica populations sampled south and north of the Swiss Alps

\begin{tabular}{|c|c|c|c|c|c|c|}
\hline \multirow[b]{2}{*}{ Population } & \multirow[b]{2}{*}{ Region } & \multirow[b]{2}{*}{ Subpopulation } & \multirow[b]{2}{*}{ Forest type } & \multirow[b]{2}{*}{ First observation ${ }^{\mathrm{a}}$} & \multicolumn{2}{|c|}{ Sampling } \\
\hline & & & & & Year & $N$ \\
\hline Lattecaldo & South & $\ldots$ & Mixed & $1940 \mathrm{~s}$ & 2003 & 42 \\
\hline Novaggio & South & $\ldots$ & Coppice & $1940 \mathrm{~s}$ & 1996 & 28 \\
\hline Lumino & South & $\ldots$ & Coppice & 1940 s & 1990 & 32 \\
\hline Gnosca & South & $\ldots$ & Coppice & $1940 \mathrm{~s}$ & 1990 & 26 \\
\hline Claro & South & $\ldots$ & Coppice & $1940 \mathrm{~s}$ & 1996 & 27 \\
\hline Murg & North & $\ldots$ & Mixed & 1989 & 2003-08 & 28 \\
\hline \multirow[t]{3}{*}{ Walchwil } & North & Ausseregg & Old orchard & 1989 & 2003-07 & 19 \\
\hline & $\ldots$ & Bühl & High forest & 2004 & 2003-07 & 14 \\
\hline & & Untertal & Coppice & $?$ & 2008 & 8 \\
\hline Weggis & North & $\ldots$ & Coppice & 1989 & 1990 & 30 \\
\hline Villars & North & $\ldots$ & Coppice & 2005 & 2007-08 & 28 \\
\hline & $\ldots$ & Malevoz & Old orchard & 1996 & 2008 & 24 \\
\hline \multirow[t]{3}{*}{ Bex } & North & Creux Boyon & Old orchard & 1997 & 2007 & 25 \\
\hline & $\ldots$ & Pré Serre & Old orchard & 1997 & 2007 & 16 \\
\hline & & Orgeolet & Old orchard & 1997 & 2007 & 19 \\
\hline Eyholz & North & $\ldots$ & Mixed & 1989 & 2007 & 27 \\
\hline
\end{tabular}

${ }^{a}$ Year of first observation of C. parasitica according to Heiniger and Rigling (33); ? indicates year unknown. 
French haplotypes of $C$. parasitica were also included in the Structure analysis.

The possible origin of the $C$. parasitica haplotypes found north of the Alps was determined as follows. If a specific haplotype belonged to the same gene pool as the haplotypes in southern Switzerland, this haplotype was considered to be a potential immigrant from southern Switzerland. However, each haplotype present north of the Alps was also checked for an eventual local origin through recombination or mutation. Recombinant haplotypes were identified by allelic patterns expected from outcrossing of two resident haplotypes. Haplotypes that showed a unique allele at one microsatellite locus but shared all other alleles with the local population were considered mutant haplotypes.

The genetic relationship among the $C$. parasitica haplotypes was visualized by constructing a median-joining network (7) as implemented in Network 4.1.0.6 (www.fluxus-engineering.com). For all loci, the weight was set to 10 . At each locus, the haplotype with the shortest allele size was considered to have a number of motif repeats of 10. For all other haplotypes, the number of motif repeats at a specific locus was extrapolated using allele size and repeat motif length (di- or trinucleotides).

\section{RESULTS}

Population structure. The 652 C. parasitica isolates analyzed belonged to 52 multilocus haplotypes (i.e., genotypes, designated CpMG1 to CpMG52) (Supplementary Table 1). South of the Alps, 40 haplotypes were identified, with 7 (Bregaglia) to 16 (Lattecaldo) haplotypes per population (Table 2). North of the Alps, populations were composed of 2 (Vinzel and Villars) to 8
(Murg) haplotypes, with a total of 21 different haplotypes. The $C$. parasitica population south of the Alps was dominated by haplotypes CpMG33, with $30.4 \%$ of the isolates, and CpMG15, with $26 \%$ (Fig. 1; Table 2). The frequency of the remaining 38 haplotypes was considerably lower, 0.3 to $5.1 \%$. A similar situation was observed north of the Alps, where haplotypes CpMG15, CpMG30, and CpMG33 were predominant (65.6\% of the isolates), while 15 of 21 haplotypes were rare (Fig. 2). The mean number of haplotypes expected in a $C$. parasitica population of 20 samples was significantly higher south than north of the Alps $(t=-5.79, P<0.001)$. Five of the seven most frequent haplotypes in France (25) were also found in Switzerland and corresponded to the two widespread haplotypes CpMG15 (RE019) and CpMG33 (RE092) and to the haplotypes CpMG27 (RE043), CpMG48 (RE103), and CpMG51 (RE079). In contrast, the French haplotypes RE028 and RE053 were not found in the Swiss $C$. parasitica population. The 12 historical $C$. parasitica isolates belonged to eight different haplotypes (CpMG3, CpMG5, CpMG15, CpMG33, CpMG36, CpMG44, CpMG45, and CpMG48) (Fig. 2). Only haplotypes CpMG15 and CpMG33 comprised more than one isolate (four and two, respectively). In the current sampling (1990 to 2008), all eight historical haplotypes were found: six occurred both south and north of the Alps (CpMG3, CpMG5, CpMG15, CpMG33, and CpMG44) and two only in southern Switzerland (CpMG36 and CpMG45).

All 10 microsatellite loci analyzed were polymorphic in the overall Swiss $C$. parasitica population (Table 2). When considering all populations, the mean $A_{\mathrm{R}}$ was identical south and north of the Alps $(t=0.64, P=0.531)$. However, if the two western populations, Gilly and Monthey (subpopulation Malevoz), were

TABLE 2. Genetic diversity and reproductive mode in 18 Cryphonectria parasitica populations from Switzerland ${ }^{\mathrm{a}}$

\begin{tabular}{|c|c|c|c|c|c|c|c|c|c|c|c|c|c|}
\hline \multirow[b]{2}{*}{ Population } & \multicolumn{8}{|c|}{ Genetic diversity $^{\mathrm{b}}$} & \multicolumn{5}{|c|}{ Reproductive mode } \\
\hline & $N$ & Hap $_{\mathrm{Obs}}$ & Hap $_{\text {Exp }}$ & Hap $_{\text {Pre }}$ & $\operatorname{Hap}_{\text {Pre }}(\%)$ & $P_{\mathrm{L}}$ & $N_{\mathrm{A}}$ & $A_{\mathrm{R}}$ & $C_{\mathrm{f}}(\%)$ & $\operatorname{Hap}_{\text {MaxTwo }}(N)$ & $M A T-1: M A T-2^{\mathrm{c}}$ & $r_{\mathrm{d}}^{\mathrm{d}}$ & $P$ \\
\hline \multicolumn{14}{|l|}{ South of the Alps } \\
\hline Bregaglia & 30 & 7 & 5.9 & CpMG15 & 40.0 & 6 & 1.8 & 1.6 & 76.7 & 16 & $8: 20 *$ & $0.15 *(0.32 * * *)$ & $1 / 4$ \\
\hline Brusio & 44 & 8 & 5.9 & CpMG15 & 40.9 & 6 & 1.8 & 1.5 & 81.8 & 16 & $17: 18$ & $0.13 * * *(0.33 * * *)$ & $1 / 5$ \\
\hline Biasca & 42 & 12 & 7.6 & CpMG33 & 54.8 & 8 & 2.1 & 1.6 & 71.4 & 16 & $7: 29 * * *$ & $0.02(0.23 * * *)$ & $1 / 5$ \\
\hline Brissago & 20 & 9 & 9.0 & CpMG15 & 35.0 & 6 & 1.6 & 1.5 & 55.0 & 16 & $3: 5$ & $0.11 * * *(0.17 * * *)$ & $0 / 4$ \\
\hline Claro & 27 & 11 & 8.9 & CpMG15 & 40.7 & 8 & 1.9 & 1.5 & 59.3 & 16 & $9: 16$ & $0.07 * * *(0.21 * * *)$ & $0 / 3$ \\
\hline Gnosca & 26 & 12 & 10.6 & $\begin{array}{l}\text { CpMG9, } \\
\text { CpMG18, } \\
\text { CpMG33 }\end{array}$ & 15.4 & 9 & 2.3 & 1.6 & 53.8 & 8 & $15: 18$ & $0.12 * * *(0.11 * * *)$ & $1 / 6$ \\
\hline Lattecaldo & 42 & 16 & 10.8 & CpMG33 & 31.0 & 9 & 2.2 & 1.6 & 61.9 & 16 & $9: 19$ & $0.09 * * *(0.21 * * *)$ & $1 / 7$ \\
\hline Lumino & 32 & 13 & 9.6 & $\begin{array}{l}\text { CpMG15, } \\
\text { CpMG33 }\end{array}$ & 28.1 & 9 & 2.2 & 1.6 & 59.4 & 16 & $22: 17$ & $0.13 * * *(0.22 * * *)$ & $1 / 5$ \\
\hline Novaggio & 28 & 12 & 9.8 & CpMG33 & 35.7 & 5 & 1.7 & 1.5 & 57.1 & 16 & $12: 16$ & $0.09 * * *(0.25 * * *)$ & $0 / 5$ \\
\hline Total & 291 & 40 & - & CpMG33 & 30.5 & 9 & 2.4 & 1.6 & 86.2 & - & $102: 158$ & $0.06^{* * *}$ & - \\
\hline \multicolumn{14}{|l|}{ North of the Alps } \\
\hline Murg & 28 & 8 & 6.5 & CpMG18 & 60.7 & 4 & 1.6 & 1.5 & 71.4 & 4 & $18: 6^{*}$ & $-0.06\left(0.15^{*}\right)$ & $1 / 3$ \\
\hline Walchwil & 41 & 5 & 4.8 & CpMG15 & 34.1 & 5 & 1.6 & 1.5 & 87.8 & 64 & $21: 15$ & $0.26 *(0.47 * * *)$ & $0 / 5$ \\
\hline Weggis & 30 & 4 & 3.3 & CpMG33 & 66.7 & 5 & 1.6 & 1.5 & 86.7 & 8 & $1: 29 * * *$ & - & $0 / 3$ \\
\hline Gilly & 21 & 5 & 4.8 & CpMG15 & 47.6 & 10 & 3.2 & 2.5 & 76.2 & 81 & $11: 8$ & $0.008(0.55 * * *)$ & $3 / 3$ \\
\hline Vinzel & 20 & 2 & 2.0 & CpMG15 & 80.0 & 4 & 1.6 & 1.6 & 92.9 & 36 & $16: 4 * * *$ & - & $1 / 2$ \\
\hline Villars & 28 & 2 & 2.0 & CpMG15 & 85.7 & 6 & 1.4 & 1.4 & 90.0 & 16 & $23: 4 * * *$ & - & $1 / 2$ \\
\hline Monthey & 94 & 5 & 4.1 & CpMG30 & 67.0 & 9 & 2.3 & 1.9 & 94.7 & 8 & $68: 22 * * *$ & $0.44 * * *(0.56 * * *)$ & $1 / 5$ \\
\hline Bex & 60 & 5 & 3.7 & CpMG30 & 43.3 & 5 & 1.5 & 1.4 & 91.7 & 4 & $13: 46^{* * * *}$ & $0.23 *(0.21 * * *)$ & $0 / 3$ \\
\hline Eyholz & 27 & 6 & 5.5 & CpMG15 & 44.4 & 5 & 1.5 & 1.4 & 77.8 & 9 & $11: 5$ & $0.14 *(0.21 * * *)$ & $0 / 4$ \\
\hline Total & 349 & 21 & - & CpMG30 & 25.8 & 10 & 1.8 & 1.6 & 94.0 & - & $182: 139$ & $0.20 * * *$ & - \\
\hline All Switzerland & 640 & 52 & - & CpMG15 & 24.6 & 10 & 3.8 & 1.9 & 91.9 & - & $284: 297$ & - & - \\
\hline
\end{tabular}

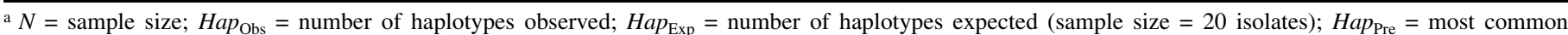
haplotype; $\operatorname{Hap}_{\text {Pre }}(\%)=$ frequency of the most common haplotype; $P_{\mathrm{L}}=$ number of polymorphic loci across 10 loci; $N_{\mathrm{A}}=$ mean number of alleles per locus;

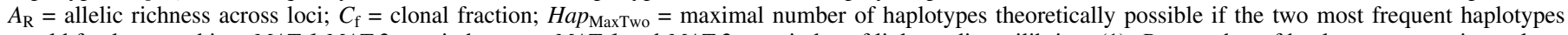
would freely recombine; MAT-1:MAT-2 = ratio between $M A T-1$ and $M A T-2 ; r_{\mathrm{d}}=$ index of linkage disequilibrium (1); $P=$ number of haplotypes occurring at least twice for which GenClone analysis statistically $\left(P_{\mathrm{Sex}}<0.05\right)$ supports a clonal origin compared with the total number of repeated haplotypes; $-=$ unknown.

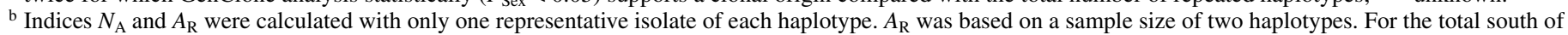
the Alps and north of the Alps, the mean value across the corresponding populations was calculated.

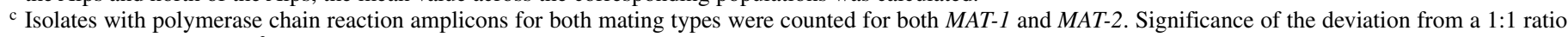
was determined with a $\chi^{2}$ test; $*$ and $* * *$ indicate $P<0.05$ and 0.001 , respectively.

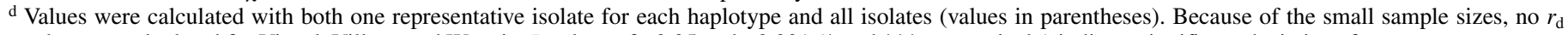
value was calculated for Vinzel, Villars, and Weggis. $P$ values of $<0.05$ and $<0.001$ (* and ***, respectively) indicate significant deviations from zero. 
excluded from the analyses, the mean $A_{\mathrm{R}}$ was significantly higher $(t=-2.63, P=0.02)$ south than north of the Alps. Of the 15 rare alleles (i.e., alleles present in no more than two populations) found across Switzerland, 11 resided in these two populations (Supplementary Table 2).

The overall $F_{\mathrm{ST}}$ value across $C$. parasitica populations was -0.03 in southern Switzerland and 0.05 in northern Switzerland. South of the Alps, the Mantel test did not reveal any significant correlation between geographical and genetic distance among populations $\left(r_{\mathrm{n}}=-0.36, P=0.926\right)$.

Reproductive mode. Perithecia of $C$. parasitica were observed in all 18 populations. Similarly, all 18 populations and also the historical isolates (seven isolates had MAT-1 and five isolates had MAT-2) harbored both mating types of $C$. parasitica (Table 2). The mating type ratios significantly differed from $1: 1$ in six populations north of the Alps and in two populations south of the Alps (Table 2). In C. parasitica populations in northern Switzerland, the most common haplotypes were generally strongly dominated by a single mating type ( 73 to $100 \%$ of the isolates) whereas, in southern Switzerland, both mating types were usually present within dominant haplotypes (dominant mating type: 54 to $82 \%$ of the isolates). For 51 isolates (in Monthey, Bregaglia, Biasca, Gnosca, Lattecaldo, Lumino, and Novaggio), PCR amplicons were obtained for both MAT-1 and MAT-2 idiomorphs. New mating type determination after independent DNA extraction for 10 of these isolates gave the same result, indicating that the presence of both MAT idiomorphs was not due to PCR contaminations. Because all microsatellite loci showed only one allele, these 51 isolates are probably heterokaryotic for mating type (44) and they may have originated through parasexual events $(26,47)$.

In five of nine $C$. parasitica populations north of the Swiss Alps, a single haplotype was predominant (60.7 to $85.7 \%$ of isolates) (Table 2). In contrast, the most frequent haplotype per population south of the Alps had a frequency of only $54.8 \%$ (Cp33, Biasca). In all populations apart from Gnosca and Lattecaldo (south of the Alps) and Murg and Bex (north of the Alps), the number of haplotypes observed was lower than the maximal number of haplotypes expected if the two predominant haplotypes were to freely recombine. Accordingly, both south and north of the Alps, a high clonal fraction was detected in all populations (north: 71.4 to $94.7 \%$; south: 53.8 to $81.8 \%$ ). However, in 15 of 18 populations, GenClone analysis could not statistically exclude the possibility that most of the identical haplotypes may be derived from sexual reproduction between resident haplotypes (Table 2). Based on the index of association statistics, the hypothesis of random mating among haplotypes could be rejected in all populations (non-clone-corrected data sets) and in 16 of 18 C. parasitica populations when using clonecorrected data sets.

Haplotype origin. Structure analysis showed that the posterior probability of the data under the admixture model increased more-or-less constantly until $K=10$ (Fig. 3). However, the strongest increase was observed between $K=1$ and $K=2$. Starting at $K=3$, the standard deviation obtained for the 10 iterations within a $K$ value became more important. Similarly, $\Delta K$ (i.e., the ad hoc quantity related to the second order rate of change of the $\log$ probability of data with respect to the number of clusters) (27) strongly decreased between $K=1$ and $K=2$, and then remained more or less constant (Fig. 3). Thus, we decided that the optimal number of clusters (i.e., genetic pools) to best represent our data and have a biological explanation was most likely $K=2$. Based on a threshold at 0.75 for the probability of assignment to a cluster, 43 haplotypes belonged to one cluster, 8 haplotypes to another cluster, and 3 haplotypes had mixed origin (Fig. 3).

The main cluster comprised all historical haplotypes and 36 of the 40 current haplotypes found in southern Switzerland, including all predominant haplotypes in the $18 \mathrm{C}$. parasitica populations analyzed. Considering the presence of haplotypes CpMG15 (RE019), CpMG33 (RE092), and CpMG48 (RE103), this cluster most likely corresponded to cluster $\mathrm{C} 1$ described by Dutech et al. (25) in France. The second cluster grouped eight haplotypes, three occurring in northwestern Switzerland (CpMG26, CpMG27, and CpMG51; populations of Gilly, Monthey, and Vinzel), three in southern Switzerland (CpMG1, CpMG20, and CpMG29; populations of Claro, Gnosca, Lattecaldo, and Lumino), and two reference haplotypes (RE028 and RE053) from France. Accordingly, the median-joining network of all haplotypes showed that these haplotypes were genetically clearly separated from the haplotypes from the main cluster (Fig. 4). This contrasts with the analyses conducted by Dutech et al. (25), where haplotype RE028 was

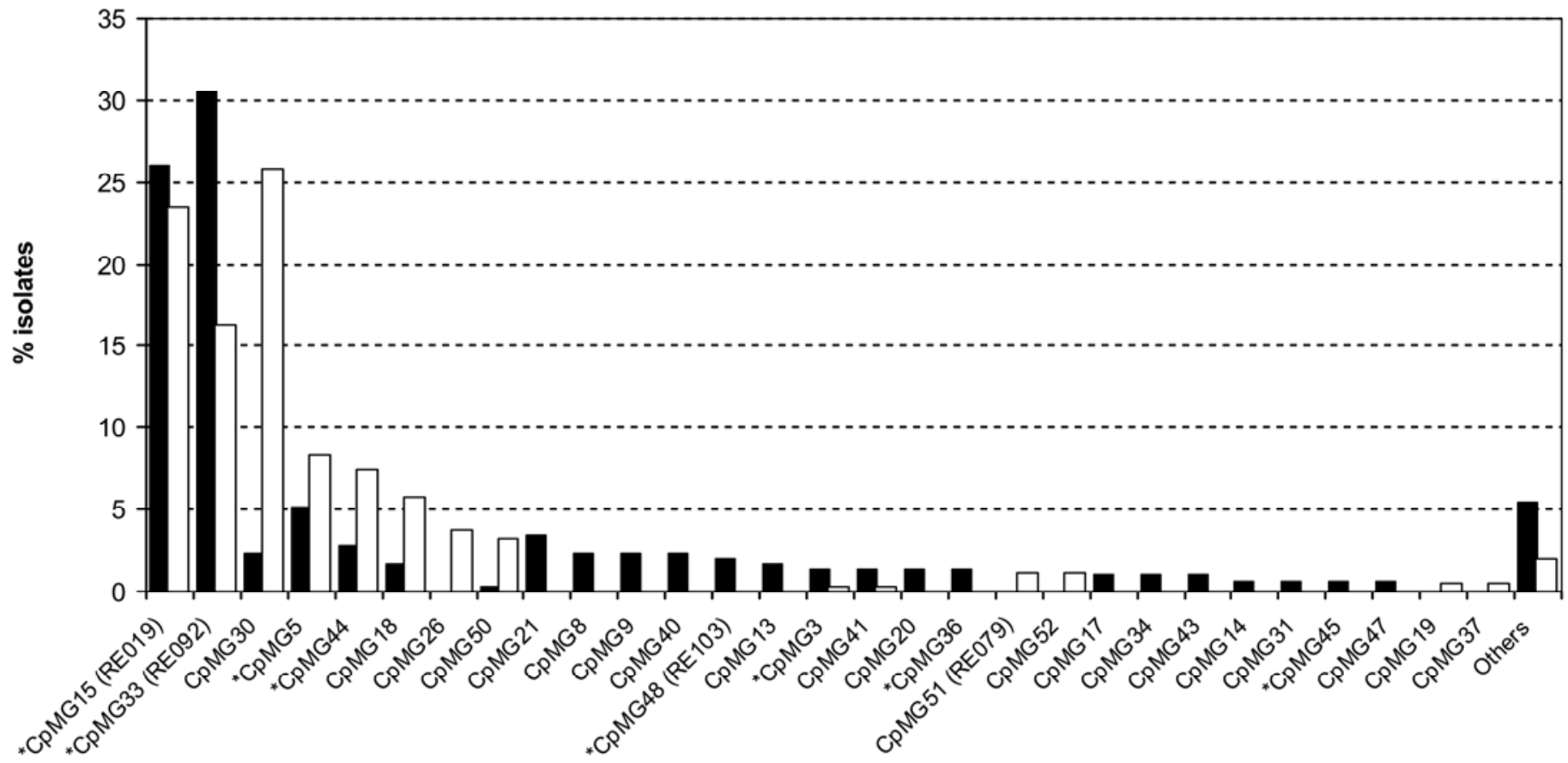

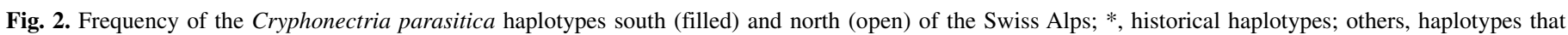
were found only once (one isolate) either south (16 haplotypes) or north ( 7 haplotypes) of the Alps. 
attributed to a different cluster (cluster C3) and haplotype CpMG51 (RE079) belonged to cluster C1. The three haplotypes with a mixed origin (i.e., alleles from both clusters) were located in Gilly (CpMG28, one isolate), Biasca (CpMG2, one isolate), and Vinzel (CpMG52, four isolates).

Of the 16 haplotypes found in northern Switzerland and attributed to the main cluster, 9 were also present in southern Switzerland. Thus, they can be considered as probable immigrants from south of the Alps. All C. parasitica populations north of the Alps were dominated by one of these nine south-alpine haplotypes. The seven north-alpine haplotypes from the main cluster that were not found in the populations from southern Switzerland (Table 3) might have resulted from a mutation event that occurred at one microsatellite locus in the locally predominant haplotype (only CpMG42 in Murg might have originated from the rare haplotype CpMG41). The three haplotypes from the second cluster found north of the Alps (CpMG26, CpMG27, and CpMG51) were not detected south of the Alps. Finally, the three haplotypes with alleles from both clusters (CpMG2, CpMG28, and CpMG52) may be the result of sexual reproduction between parent haplotypes of the two clusters. For example, based on the allelic patterns in Gilly, CpMG28 (a single isolate) may be the result of outcrossing between two haplotypes genetically close to CpMG15 (dominant haplotype, main cluster) and CpMG26 (second cluster). Haplotype CpMG28 shared four alleles (at loci CPG3, CPG4, CPG14, and CPE3) with CpMG26 and three alleles (at loci CPE4, CPE5, and CPE8) with CpMG15. At three loci (CPE1,
CPG6, and I05-65), CpMG28 had different alleles from both CpMG26 and CpMG15.

\section{DISCUSSION}

The historical C. parasitica population in southern Switzerland had a similar allelic composition to the current post-epidemic population in this area. In total, 18 of the 24 current alleles were already present in the historical haplotypes, and the Structure analysis showed that 36 current haplotypes clustered with the historical haplotypes. Most likely, southern Switzerland was rapidly colonized by the two currently widespread haplotypes CpMG15 and CpMG33. The predominance of a single vc type within these two dominant haplotypes (CpMG15: 83\% of the isolates are EU-2; CpMG33: 69\% of the isolates are EU-5) (data not shown) suggests that the $C$. parasitica population in southern Switzerland was mainly founded by two clones. As previously observed by Milgroom et al. (48) in southeastern Europe, a low genetic diversity did not impede the successful establishment of C. parasitica in southern Switzerland. For invasive plant species, on the other hand, their ability to become established has been found to be improved with admixed founder populations $(20,36)$.

Given that haplotypes CpMG15 and CpMG33 are frequently detected in northern Italy and southeastern France in association with vc types EU-2 and EU-5, respectively $(25,56)$, the two clones that founded the $C$. parasitica population in southern Switzerland probably originated from one of these two regions.
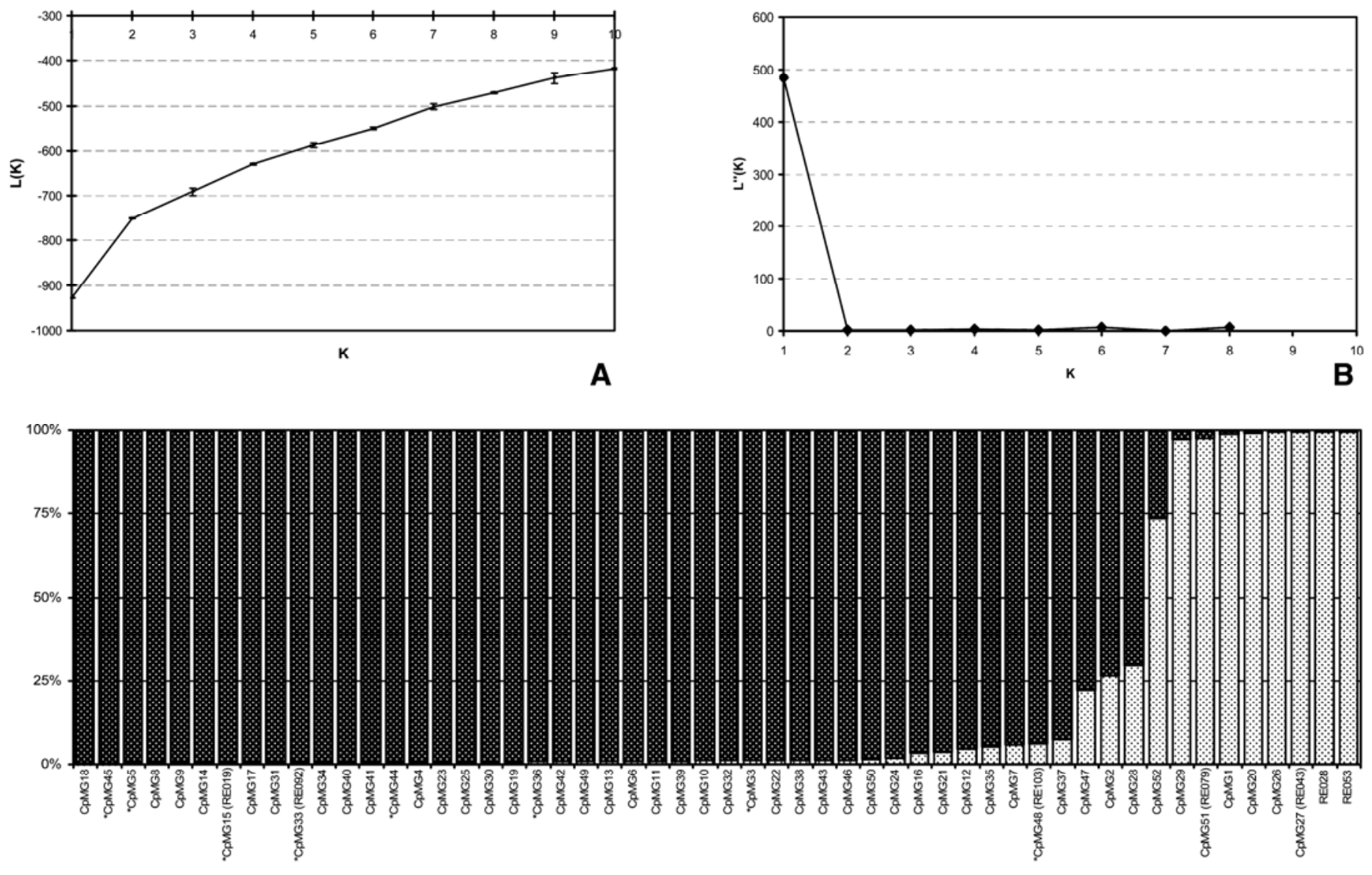

C

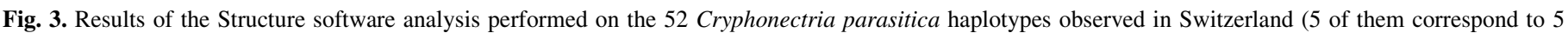

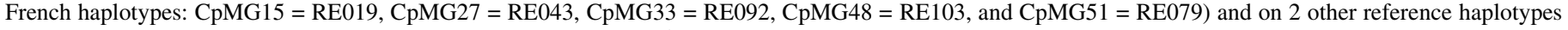

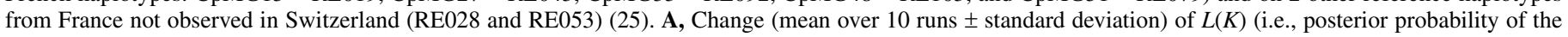

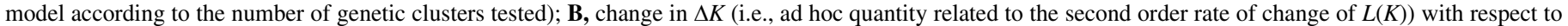

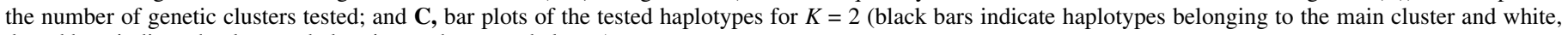
dotted bars indicate haplotypes belonging to the second cluster). 
Northern Italy, where $C$. parasitica was first detected in Europe (32), is geographically closer and the source population was most likely located there. Because our Structure analysis indicated that the vast majority of the $C$. parasitica haplotypes currently found in southern Switzerland share the same genetic pool, it is reasonable to assume that these haplotypes probably also originated from northern Italy. The four haplotypes from southern Switzerland that, according to the Structure analysis, did not cluster with the other current haplotypes, most likely have a different origin. Three of them (CpMG1, CpMG20, and CpMG29) seem to be immigrants from the same source population as the four haplotypes from northwestern Switzerland (see below). Therefore, a few additional introductions from a different genetic pool may have occurred in southern Switzerland. One haplotype (CpMG2) may be a sexual recombinant between two parental haplotypes from the two different genetic pools.

Most newly founded $C$. parasitica populations north of the Alps were characterized by low genetic diversity compared with the older, established populations in southern Switzerland. $C$. parasitica has previously been found to have a low genetic diversity in other newly established populations in Europe $(13,48)$, probably as a results of (i) a population bottleneck during early introduction (founder effect) and (ii) random genetic drift during successive stages of establishment because of the small local population size $(24,50)$. Surprisingly, two young $C$. parasitica populations in northwestern Switzerland were more diverse than all other populations north of the Alps. This higher diversity was due to the presence of five haplotypes, which had unique alleles at most loci. Here, multiple introductions had probably mixed haplotypes from genetically different source populations, thereby increasing genetic diversity in the newly founded populations. These two populations are of particular interest for investigating whether an admixture of haplotypes significantly influences the establishment and spread of hypovirulence.

All newly established $C$. parasitica populations in northern Switzerland seem to have been initially founded by haplotypes originating either directly from southern Switzerland or from northern Italy. The spatial population structure of $C$. parasitica suggests a stochastic colonization of the chestnut stands north of the Alps. As expected in such a scenario, the new populations were mostly initiated by the haplotypes widespread in the source populations. The predominance of identical haplotypes north and south of the Alps suggests that $C$. parasitica haplotypes might well adapt to different environmental conditions. After arrival, the first $C$. parasitica haplotypes rapidly invaded a new area by asexual reproduction (34). This hypothesis is supported by the strong predominance of a single mating type within the most frequent haplotypes in the newly founded populations. Unfortunately, Geneclone analysis could not statistically demonstrate the occurrence of clonality; the statistical power of the test is low when confronted with high clonal dominance (6). Thus, this does not necessarily indicate that the most common haplotypes were generated by distinct sexual events.

As in plant species $(8,38)$, in partially clonal invasive fungi, asexual reproduction may provide reproductive assurance at the beginning of an invasion when mating opportunities are restricted and, at the same time, allows the population to grow fast. Successively, haplotypic diversity in the new populations increased through additional introductions, sexual reproduction, or mutation. The less common haplotypes most likely arrived or arose after the establishment of the predominant haplotypes. This conclusion is supported by the fact that the rare haplotypes were not detected at the first sampling although most cankers were sampled (data not shown). The Structure analysis indicated that additional introductions from the same source population (south of the Alps or northern Italy) probably occurred in most populations. In northwestern Switzerland, the four haplotypes with special alleles were grouped in another cluster, suggesting intro- ductions from a different genetic pool. These haplotypes originated either (i) from southwestern France, where their widespread occurrence has been reported (25), or (ii) from southern Switzerland, where some of the special alleles occur with very low frequency. Considering the strong cultural relationships between French-speaking northwestern Switzerland and France, the first hypothesis seems to be more realistic. The fact that haplotype CpMG51 (RE079) was attributed in our analyses to the same cluster as haplotype CpMG27 (RE043) but was not in the analyses conducted by Dutech et al. (25) may be explained by differences in the composition of the data sets (59).

Despite the presence of both mating types in all populations, the formation of new haplotypes through sexual reproduction seems to be rather rare, both among and within different genetic pools, as previously reported by Dutech et al. (25) in France. In 14 of 18 populations, if the two dominant haplotypes were to freely recombine, more haplotypes would be expected than those currently observed. Accordingly, the index of association statistics indicated that random sexual reproduction did not occur in most populations. Although haplotypes from different genetic pools

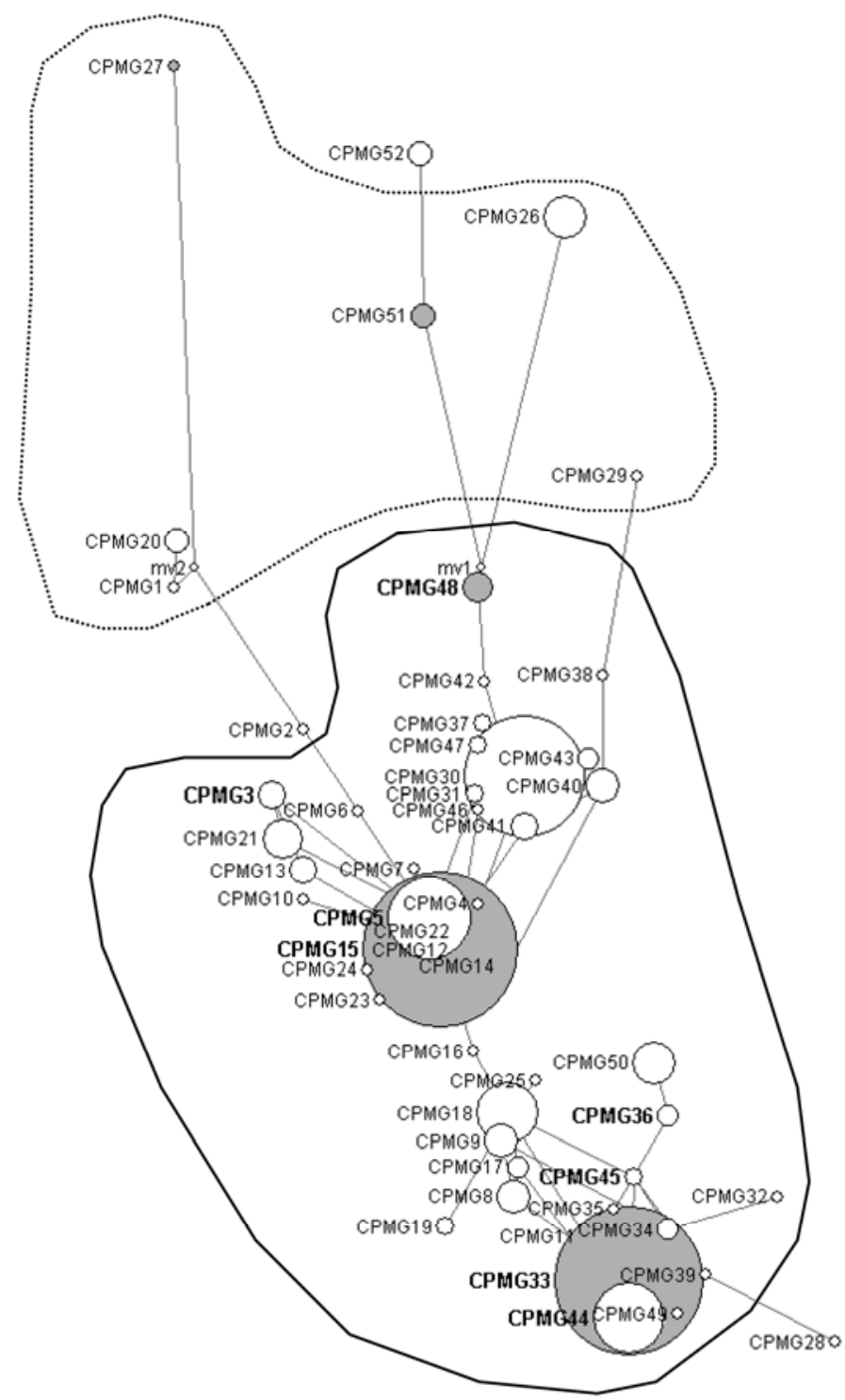

Fig. 4. Median-joining network of the 52 Cryphonectria parasitica haplotypes found in Switzerland. Sizes of the circles indicate the frequencies of the haplotypes; gray circles, haplotypes that were also found in France (25); Mv, missing or not sampled haplotypes; bold, historical haplotypes; continuous (main cluster) and dashed (secondary cluster) lines indicate the two clusters of haplotypes identified by the Structure software analysis. 
TABLE 3. Possible origins of Cryphonectria parasitica haplotypes found in the populations north of the Swiss Alps

\begin{tabular}{|c|c|c|c|c|c|c|c|c|c|c|c|c|c|}
\hline \multirow[b]{2}{*}{ Haplotype } & \multirow[b]{2}{*}{ South $^{\mathrm{a}}$} & \multicolumn{9}{|c|}{ Presence north of the Alps (population, frequency) } & \multicolumn{3}{|c|}{ Possible local origins of the haplotypes } \\
\hline & & Murg & Walchwil & Weggis & Gilly & Vinzel & Villars & Monthey & Bex & Eyholz & Historic $^{b}$ & Mutation $^{\mathrm{c}}$ & Recomb. $^{\mathrm{d}}$ \\
\hline CpMG3 & Yes & 0 & 0 & 0 & 0 & 0 & 0 & 0 & 0 & 0.04 & Yes & No & No \\
\hline CpMG5 & Yes & 0 & 0.22 & 0.27 & 0 & 0 & 0 & 0 & 0 & 0.44 & Yes & No & No \\
\hline CpMG7 & No & 0 & 0 & 0.03 & 0 & 0 & 0 & 0 & 0 & 0 & Yes & Yes; CpMG5, CPE8, 3 & No \\
\hline CpMG11 & No & 0.04 & 0 & 0 & 0 & 0 & 0 & 0 & 0 & 0 & Yes & Yes; CpMG18, CPG4, 8 & No \\
\hline CpMG12 & No & 0 & 0 & 0 & 0 & 0 & 0 & 0 & 0.02 & 0 & Yes & Yes; CpMG15, CPG4, 1 & No \\
\hline CpMG15 & Yes & 0.07 & 0.34 & 0 & 0.48 & 0.8 & 0.86 & 0.12 & 0.02 & 0.15 & Yes & No & No \\
\hline CpMG16 & No & 0.04 & 0 & 0 & 0 & 0 & 0 & 0 & 0 & 0 & Yes & Yes; CpMG18, CPG6, 5 & No \\
\hline CpMG18 & Yes & 0.6 & 0 & 0 & 0 & 0 & 0 & 0 & 0 & 0.11 & Yes & No & No \\
\hline CpMG19 & No & 0.04 & 0 & 0.03 & 0 & 0 & 0 & 0 & 0 & 0 & Yes & Yes; CpMG18, I07-650, 7 & No \\
\hline CpMG26 & No & 0 & 0 & 0 & 0.24 & 0 & 0 & 0.09 & 0 & 0 & No & No & No \\
\hline CpMG27 & No & 0 & 0 & 0 & 0.05 & 0 & 0 & 0 & 0 & 0 & No & No & No \\
\hline CpMG28 & No & 0 & 0 & 0 & 0.05 & 0 & 0 & 0 & 0 & 0 & No & No & Yes \\
\hline CpMG30 & Yes & 0 & 0 & 0 & 0 & 0 & 0 & 0.67 & 0.42 & 0.04 & Yes & No & No \\
\hline CpMG33 & Yes & 0 & 0.1 & 0.67 & 0 & 0 & 0.14 & 0.11 & 0.22 & 0.22 & Yes & No & No \\
\hline CpMG37 & No & 0 & 0 & 0 & 0 & 0 & 0 & 0.02 & 0 & 0 & Yes & Yes; CpMG30, CPG4, 3 & No \\
\hline CpMG41 & Yes & 0.04 & 0 & 0 & 0 & 0 & 0 & 0 & 0 & 0 & Yes & No & No \\
\hline CpMG42 & No & 0.04 & 0 & 0 & 0 & 0 & 0 & 0 & 0 & 0 & Yes & Yes; CpMG41, I07-650,7 & No \\
\hline CpMG44 & Yes & 0.13 & 0.07 & 0 & 0 & 0 & 0 & 0 & 0.32 & 0 & Yes & No & No \\
\hline CpMG50 & Yes & 0 & 0.27 & 0 & 0 & 0 & 0 & 0 & 0 & 0 & Yes & No & No \\
\hline CpMG51 & No & 0 & 0 & 0 & 0.18 & 0 & 0 & 0 & 0 & 0 & No & No & No \\
\hline CpMG52 & No & 0 & 0 & 0 & 0 & 0.2 & 0 & 0 & 0 & 0 & No & No & Yes \\
\hline
\end{tabular}

a Presence south of the Alps.

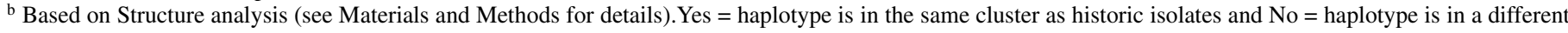
cluster.

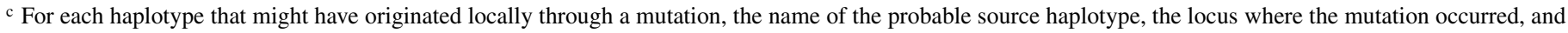
the number or mutational steps (difference in motif repeat number) are given.

${ }^{\mathrm{d}}$ Recombination. Structure analysis could not clearly attribute recombinant haplotypes to a specific genetic pool.

coexisted in seven populations, the Structure analysis revealed only three intermediate haplotypes (i.e., with alleles from two genetic pools).

In southern Switzerland, the frequency of sexual reproduction may have been underestimated because of the high genetic similarity of most $C$. parasitica haplotypes. In fact, recombination among haplotypes that differ at only one microsatellite locus would generate only the two parental haplotypes and no new haplotypes (e.g., CpMG30 × CpMG33 or CpMG33 $\times$ CpMG44). On the other hand, north of the Alps, the most likely recent encounter of the divergent haplotypes may account for the present scarcity of intermediate haplotypes. The numerous perithecia observed in all populations may result from crossing within haplotypes or selfing of heterokaryons carrying both mating types $(42,43)$. New haplotypes arising from mutations in the locally predominant haplotype might be present in a few $C$. parasitica populations north of the Alps. However, a unique allele at a single microsatellite locus is not an absolutely certain indication of a local origin through mutation, because this allele may also have originated from a source population where it is rare or not present anymore and, thus, not sampled.

The fungus has reached chestnut stands north of the Alps either naturally or due to human activity. Long-distance spread of $C$. parasitica can occur through wind-dispersed sexual ascospores or asexual spores carried by birds or other vectors (31). Alternatively and more likely, the introduction of $C$. parasitica north of the Alps may have occurred through the movement of chestnut plants from the south to the north of the Alps. Bissegger and Sieber (12) detected latent infections of $C$. parasitica on apparently healthy chestnut shoots in Ticino, which suggests that the pathogen could effectively spread on seemingly asymptomatic plants. In either case, the Alps were not an efficient barrier for the dispersal of the pathogen in the long term.

In most European regions of first introduction, disease severity is currently reduced by hypovirulence (32). In Switzerland, hypovirulence has become naturally established south of the Alps (11) and is currently being artificially introduced in chestnut stands north of the Alps (33). Because the hypovirus preferentially spreads between $C$. parasitica strains with the same vc type, a high vc type diversity may be a potential obstacle for the establishment and diffusion of hypovirulence (18). Although our analyses were based on microsatellites, vc tests showed that the haplotypes, which probably originated from southwestern France (i.e., CpMG26, CpMG27, and CpMG51) had very different vc types than those of the dominant haplotypes in Switzerland (data not shown). Therefore, this study indicates that migration of new $C$. parasitica haplotypes, especially from divergent genetic pools, can increase genetic diversity (including vc type diversity) and, thus, potentially disturb the biological control system both in post-epidemic (well-established) and newly founded populations. Consequently, the correct application of appropriate quarantine regulations should continue even after establishment of an invasive pathogen in a new geographic area.

\section{ACKNOWLEDGMENTS}

We thank E. Jung for technical assistance in the laboratory; R. Holderegger, C. Dutech, and two anonymous reviewers for valuable comments on the manuscript; the Competence Center Environment and Sustainability (CCES) of the ETH domain for financial support (project GEDIHAP); and S. Dingwall for English revision.

\section{LITERATURE CITED}

1. Agapow, P.-M., and Burt, A. 2001. Indices of multilocus linkage disequilibrium. Mol. Ecol. Notes 1:101-102.

2. Akilli, S., Katircioglu, Y. Z., and Maden, S. 2009. Vegetative compatibility types of Cryphonectria parasitica, causal agent of chestnut blight, in the Black Sea region of Turkey. For. Pathol. 39:290-296.

3. Anagnostakis, S. L. 1987. Chestnut blight: The classical problem of an introduced pathogen. Mycologia 79:23-37.

4. Anderson, P. K., Cunningham, A. A., Patel, N. G., Morales, F. J., Epstein, P. R., and Daszak, P. 2004. Emerging infectious diseases of plants: Pathogen pollution, climate change and agrotechnology drivers. Trends Ecol. Evol. 19:535-544.

5. Arnaud-Haond, S., and Belkhir, K. 2007. GenClone: a computer program to analyse genotypic data, test for clonality and describe spatial clonal organization. Mol. Ecol. Notes 7:15-17.

6. Arnaud-Haond, S., Duarte, C. M., Alberto, F., and Serrao, E. A. 2007. Standardizing methods to address clonality in population studies. Mol. Ecol. 16:5115-5139. 
7. Bandelt, H. J., Forster, P., and Röhl, A. 1999. Median-joining networks for inferring intraspecific phylogenies. Mol. Biol. Evol. 16:37-48.

8. Barrett, S. C. H., Colautti, R. I., and Eckert, C. G. 2008. Plant reproductive systems and evolution during biological invasion. Mol. Ecol. 17:373-383.

9. Belkhir, K., Borsa, P., Chikhi, L., Raufaste, N., and Bonhomme, F. 1996. GENETIX 4.02, logiciel sous Windows TM pour la génétique des populations. CNRS/Université de Montpellier, Montpellier, France.

10. Bissegger, M., and Heiniger, U. 1991. Chestnut blight (Cryphonectria parasitica) north of the Swiss Alps. For. Pathol. 21:250-252.

11. Bissegger, M., Rigling, D., and Heiniger, U. 1997. Population structure and disease development of Cryphonectria parasitica in European chestnut forests in the presence of natural hypovirulence. Phytopathology 87:50-59.

12. Bissegger, M., and Sieber, T. 1997. Assemblages of endophytic fungi in coppice shoots of Castanea sativa. Mycologia 86:648-655.

13. Bragança, H., Simões, S., Onofre, N., Tenreiro, R., and Rigling, D. 2007. Cryphonectria parasitica in Portugal: diversity of vegetative compatibility types, mating types, and occurrence of hypovirulence. For. Pathol. 37:391-402.

14. Breuillin, F., Dutech, C., and Robin, C. 2006. Genetic diversity of the chestnut blight fungus Cryphonectria parasitica in four French populations assessed by microsatellite markers. Mycol. Res. 110:288-296.

15. Burt, A., Carter, D. A., Koenig, G. L., White, T. J., and Taylor, J. W. 1996. Molecular markers reveal cryptic sex in the human pathogen Coccidiodes immitis. Proc. Natl. Acad. Sci. USA 93:770-773.

16. Choi, G. H., and Nuss, D. L. 1992. Hypovirulence of chestnut blight fungus conferred by an infectious viral cDNA. Science 257:800-803.

17. Conedera, M., and Krebs, P. 2009. Switzerland. Scripta Hortic. 9:149154.

18. Cortesi, P., McCulloch, C. E., Song, H., Lin, H., and Milgroom, M. G. 2001. Genetic control of horizontal virus transmission in the chestnut blight fungus Cryphonectria parasitica. Genetics 159:107-118.

19. Cortesi, P., Rigling, D., and Heiniger, U. 1998. Comparison of vegetative compatibility types in Italian and Swiss subpopulations of Cryphonectria parasitica. Eur. J. For. Pathol. 28:167-176.

20. Crawford, K. M., and Whitney, K. D. 2010. Population genetic diversity influences colonization success. Mol. Ecol. 19:1253-1263.

21. Davis, J. E., Kubisiak, T. L., and Milgroom, M. G. 2005. Polymorphic sequence-characterized codominant loci in the chestnut blight fungus, Cryphonectria parasitica. Mol. Ecol. Notes 5:195-197.

22. Desprez-Loustau, M.-L., Courtecuisse, R., Robin, C., Husson, C., Moreau, P.-A., Blancard, D., Selosse, M.-A., Lung-Escarmant, B., Piou, D., and Sache, I. 2010. Species diversity and drivers of spread of alien fungi (sensu lato) in Europe with a particular focus on France. Biol. Invasions 12:157-172.

23. Desprez-Loustau, M.-L., Robin, C., Buées, M., Courtecuisse, R., Garbaye, J., Suffert, F., Sache, I., and Rizzo, D. M. 2007. The fungal dimension of biological invasions. Trends Ecol. Evol. 22:472-480.

24. Dlugosch, K. M., and Parker, I. M. 2008. Founding events in species invasions: genetic variation, adaptive evolution, and the role of multiple introductions. Mol. Ecol. 17:431-449.

25. Dutech, C., Fabreguettes, O., Capdevielle, X., and Robin, C. 2010. Multiple introductions of divergent genetic lineages in an invasive fungal pathogen, Cryphonectria parasitica, in France. Heredity 105:220-228.

26. Dutech, C., Rossi, J.-P., Fabreguettes, O., and Robin, C. 2008. Geostatistical genetic analysis for inferring the dispersal pattern of a partially clonal species: example of the chestnut blight fungus. Mol. Ecol. 17:4597-4607.

27. Evanno, G., Regnaut, S., and Goudet, J. 2005. Detecting the number of clusters of individuals using the software STRUCTURE: a simulation study. Mol. Ecol. 14:2611-2620.

28. Falush, D., Stephens, M., and Pritchard, J. K. 2003. Inference of population structure: Extensions to linked loci and correlated allele frequencies. Genetics 164:1567-1587.

29. Gardes, M., and Bruns. 1993. ITS primers with enhanced specificity for basidiomycetes - application to the identification of mycorrhizae and rusts. Mol. Ecol. 2:113-118.

30. Goudet, J. 2001. FSTAT, a program to estimate and test gene diversities and fixation indices Version 2.9.3. Department of Ecology and Evolution, University of Lausanne, Switzerland.

31. Heald, F. D., Gardner, M. W., and Studhalter, R. A. 1915. Air and wind dissemination of ascospores of the chestnut blight fungus. J. Agric. Res. 3:493-526.

32. Heiniger, U., and Rigling, D. 1994. Biological control of chestnut blight in Europe. Annu. Rev. Phytopathol. 32:581-599.

33. Heiniger, U., and Rigling, D. 2009. Application of the Cryphonectria hypovirus (CHV-1) to control the chestnut blight, experience from Switzerland. Acta Hortic. 815:233-246.

34. Hoegger, P. J., Rigling, D., Holdenrieder, O., and Heiniger, U. 2000.
Genetic structure of newly established populations of Cryphonectria parasitica. Mycol. Res. 104:1108-1116.

35. Hulme, P. E., Bacher, S., Kenis, M., Klotz, S., Kühn, I., Minchin, D., Nentwig, W., Olenin, S., Panov, V., Pergl, J., Pyšek, P., Roques, A., Sol, D., Solarz, W., and Vilà, M. 2008. Grasping at the routes of biological invasions: a framework for integrating pathways into policy. J. Appl. Ecol. 45:403-414.

36. Keller, S. R., and Taylor, D. M. 2010. Genomic admixture increases fitness during a biological invasion. J. Evol. Biol. 23:1720-1731.

37. Kubisiak, T. L., Dutech, C., and Milgroom, M. G. 2007. Fifty-three polymorphic microsatellite loci in the chestnut blight fungus, Cryphonectria parasitica. Mol. Ecol. Notes 7:428-432.

38. Liu, J., Dong, M., Miao, S. L., Li, Z. Y., Song, M. H., and Wang, R. Q. 2006. Invasive alien plants in China: role of clonality and geographical origin. Biol. Invasions 8:1461-1470.

39. Liu, Y. C., Cortesi, P., Double, M. L., MacDonald, W. L., and Milgroom, M. G. 1996. Diversity and multilocus genetic structure in populations of Cryphonectria parasitica. Phytopathology 86:1344-1351.

40. Loo, J. A. 2009. Ecological impacts of non-indigenous invasive fungi as forest pathogens. Biol. Invasions 11:81-96.

41. Mantel, N. 1967. Detection of disease clustering and a generalized regression approach. Cancer Res. 27:209-220.

42. Marra, R. E., Cortesi, P., Bissegger, M., and Milgroom, M. G. 2004. Mixed mating in natural populations of the chestnut blight fungus Cryphonectria parasitica. Heredity 93:189-195.

43. Marra, R. E., and Milgroom, M. G. 1999. PCR amplification of the mating-type idiomorphs in Cryphonectria parasitica. Mol. Ecol. 8:19471950.

44. McGuire, I. C., Marra, R. E., and Milgroom, M. G. 2004. Mating-type heterokaryosis and selfing in Cryphonectria parasitica. Fungal Genet. Biol. 41:521-533.

45. Milgroom, M. G., and Cortesi, P. 1999. Analysis of population structure of the chestnut blight fungus based on vegetative incompatibility genotypes. Proc. Natl. Acad. Sci. USA 96:10518-10523.

46. Milgroom, M. G., and Cortesi, P. 2004. Biological control of chestnut blight with hypovirulence: a critical analysis. Annu. Rev. Phytopathol. 42:311-338.

47. Milgroom, M. G., Sotirovski, K., Risteski, M, and Brewer, M. T. 2009. Heterokaryons and parasexual recombinants of Cryphonectria parasitica in two clonal populations in southeastern Europe. Fungal Genet. Biol. 46:849-854.

48. Milgroom, M. G., Sotirovski, K., Spica, D., Davis, J. E., Brewer, M. T., Milev, M., and Cortesi, P. 2008. Clonal population structure of the chestnut blight fungus in expanding ranges in southeastern Europe. Mol. Ecol. 17:4446-4458.

49. Orwig, D. A. 2002. Ecosystem to regional impacts of introduced pests and pathogens: Historical context, questions and issues. J. Biogeogr. 29:14711474.

50. Parker, I. M., and Gilbert, G. S. 2004. The evolutionary ecology of novel plant-pathogen interactions. Annu. Rev. Ecol. Syst. 35:675-700.

51. Pritchard, J. K., Stephens, M., and Donnelly, P. 2000. Inference of population structure using multilocus genotype data. Genetics 155:945959.

52. Prospero, S., Conedera, M., Heiniger, U., and Rigling, D. 2006. Saprophytic activity and sporulation of Cryphonectria parasitica on dead chestnut wood in forests with naturally established hypovirulence. Phytopathology 96:1337-1344.

53. Raup, D. M. 1975. Taxonomic diversity estimation using rarefaction. Paleobiology 1:333-342.

54. Robin, C., Capdevielle, X., Martin, M., Traver, C., and Colinas, C. 2009. Cryphonectria parasitica vegetative compatibility type analysis of populations in south-western France and northern Spain. Plant Pathol. 58:527-535

55. Robin, C., and Heiniger, U. 2001. Chestnut blight in Europe: Diversity of Cryphonectria parasitica, hypovirulence and biocontrol. For. Snow Landsc. Res. 76:361-367.

56. Rostagno, L. 2009. Interaction between Cryphonectria parasitica and CHV1: a model for virus caused hypovirulence. Ph.D. thesis, Università degli Studi di Torino, Italy.

57. Rousset, F. 1997. Genetic differentiation and estimation of gene flow from $F$-statistics under isolation by distance. Genetics 145:1219-1228.

58. Sakai, A. K., Allendorf, F. W., Holt, J. S., Lodge, D. M., Molofsky, J., With, K. A., Baughman, S., Cabin, R. J., Cohen, J. E., Ellstrand, N. C., McCauley, D. E., O’Neil, P., Parker, I. M., Thompson, J. N., and Weller, S. G. 2001. The population biology of invasive species. Annu. Rev. Ecol. Evol. S. 32:305-332.

59. Schwartz, M. K., and McKelvey, K. S. 2009. Why sampling scheme matters: The effect of sampling scheme on landscape genetic results. Conserv. Genet. 10:441-452.

60. Sotirovski, K., Papazova-Anakieva, I., Grünwald, N. J., and Milgroom, 
M. G. 2004. Low diversity of vegetative compatibility types and mating type of Cryphonectria parasitica in the southern Balkans. Plant Pathol. 53:325-333.

61. Von Broembsen, S. L. 1989. Invasions of natural ecosystems by plant pathogens. Pages 77-83 in: Biological Invasions: A Global Perspective. J. L. Drake, H. A. Mooney, F. di Castri, R. H. Groves, F. J. Kruger, M.
Rejmánek, and M. Williamson eds. John Wiley, Chichester, UK.

62. Weir, B. S., and Cockerham, C. C. 1984. Estimating F-statistics for the analysis of population structure. Evolution 38:1358-1370.

63. Westphal, M. I., Browne, M., MacKinnon, K., and Noble, I. 2008. The link between international trade and the global distribution of invasive alien species. Biol. Invasions 10:391-398. 